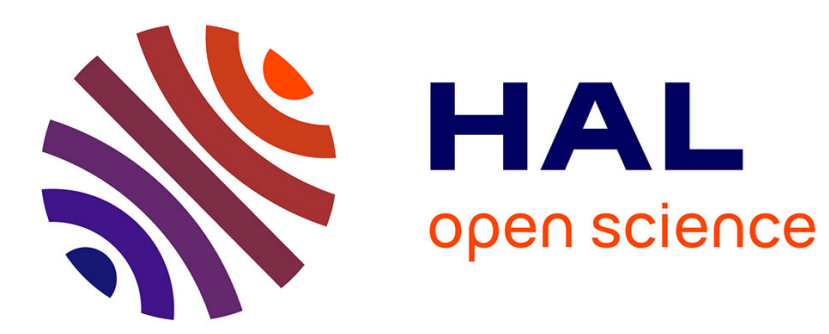

\title{
Mathematical and numerical aspects of one-dimensional laminar flame simulation
}

\author{
M. Sermange
}

\section{To cite this version:}

M. Sermange. Mathematical and numerical aspects of one-dimensional laminar flame simulation. RR-0446, INRIA. 1985. inria-00076109

\section{HAL Id: inria-00076109 \\ https://hal.inria.fr/inria-00076109}

Submitted on 24 May 2006

HAL is a multi-disciplinary open access archive for the deposit and dissemination of scientific research documents, whether they are published or not. The documents may come from teaching and research institutions in France or abroad, or from public or private research centers.
L'archive ouverte pluridisciplinaire HAL, est destinée au dépôt et à la diffusion de documents scientifiques de niveau recherche, publiés ou non, émanant des établissements d'enseignement et de recherche français ou étrangers, des laboratoires publics ou privés. 


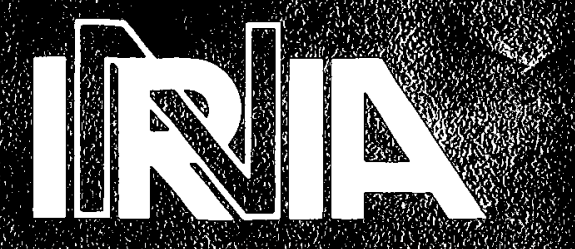

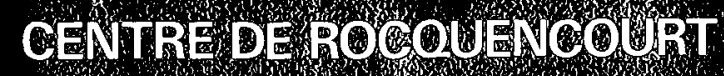

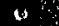

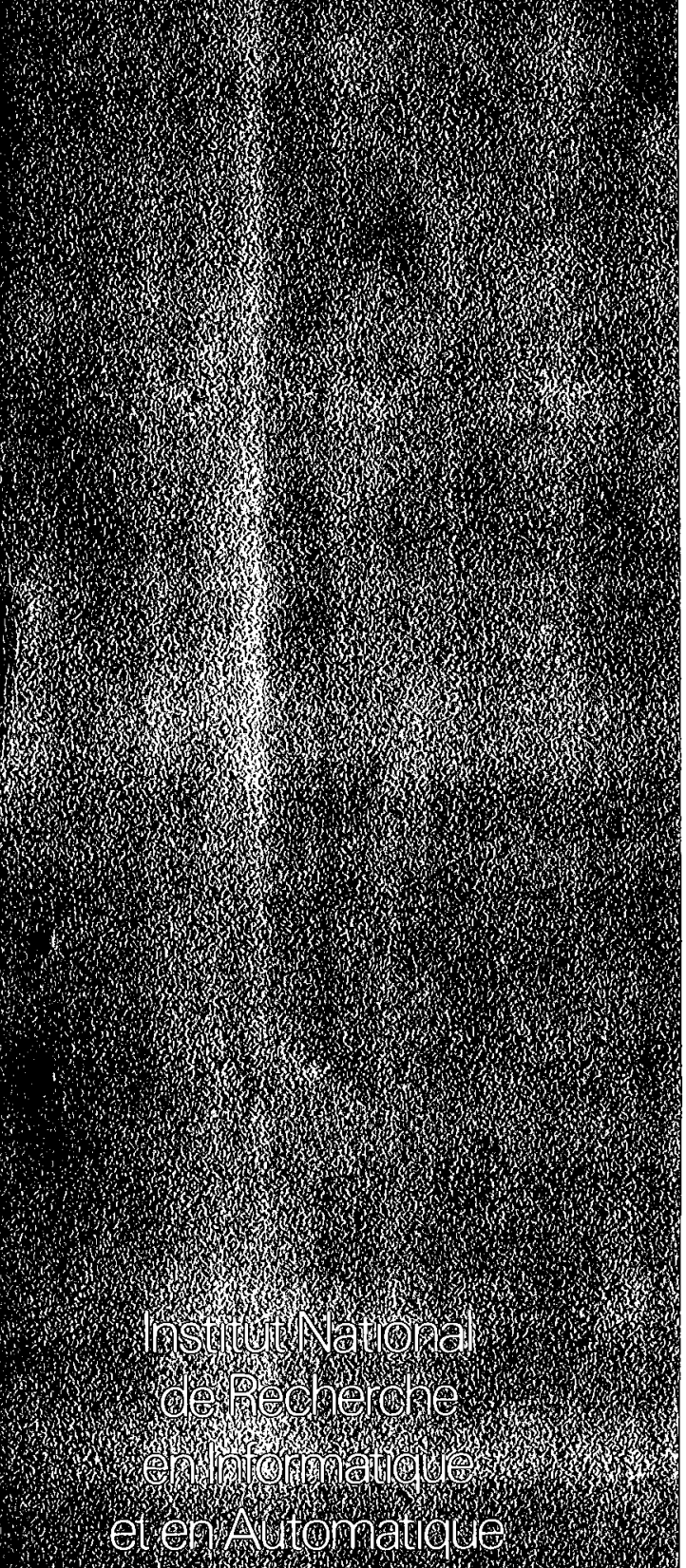

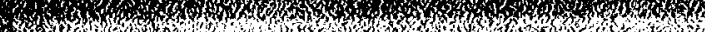

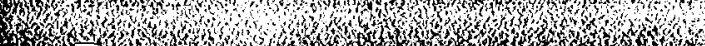

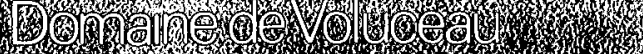

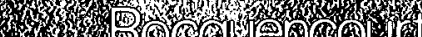
3 1.

化 D) $5,2(3,0)$ $+4$

\section{Rapports de Recherche}

$$
\mathrm{N}^{\circ} 446
$$

\section{MATHEMATICAL AND NUMERICAL ASPECTS OF ONE-DIMENSIONAL LAMINAR FLAME SIMULATION}

Michel SERMANGE

Septembre 1985 


\begin{abstract}
F
MATHEMATICAL AND NUMERICAL ASPECTS OF ONE-DIMENSIONAL LAMINAR FLAME SIMULATION

$++++++++t$
\end{abstract}

Michel SERMANGE

Abstract :

The aim of this paper is to solve several mathematical and numerical questions related to the simulation of stationary and unstationary premixed flat flames. Most of the results are obtained in the general context of complex chemical and diffusion mechanisms. The main mathematical results concern : (i) the a priori positivity of the mass fractions, (ii) the sensitivity of the flame speed to the computational domain. The numerical method that I propose for solving the stationary problem is a new combination of the pseudounstationary approach, the Newton iterations and the adaptive gridding. The computation of $\mathrm{H}_{2}-\mathrm{O}_{2}-\mathrm{N}_{2}$ flames with various initial concentrations (including the chemical extinction zone) shows the efficiency of this method.

Résumé :

Le but de ce papier est de résoudre plusieurs questions mathématiques et numériques liées à la simulation des flammes planes prémélangées stationnaires et instationnaires. La plupart des résultats sont obtenus dans le contexte général de mêcanismes chimiques et diffusifs complexes. Les résultats mathématiques principaux concernent : (i) la positivité a priori des fractions massiques, (ii) la sensibilité de la vitesse de flame au domaine de calcul. La méthode numérique que je propose pour résoudre le problème stationnaire est une combinaison originale de I'approche pseudoinstationnaire, des itérations de Newton et du maillage adaptatif. Le calcul de flammes $\mathrm{H}_{2}-\mathrm{O}_{2}-\mathrm{N}_{2}$ avec différentes concentrations initiales (y compris la zone d'extinction chimique) montre I'efficacité de cette méthode.

1980 Mathematical Subject Classification : 80A25, $65 \mathrm{~L} 10$. 


\section{INTRODUCTION}

The question of propagation (or no propagation) of a planar flame in a premixed gazeous mixture covers a great variety of situations for the following reasons :

(1) each different composition of the fresh mixture gives rise to

a different physical phenomenon;

(i1) the diffusion and chemical mechanisms can be described by a rather realistic or simplified model.

As an example of (ii), the hydrogen-air flame

$2 \mathrm{H}_{2}+\mathrm{O}_{2} \rightarrow 2 \mathrm{H}_{2} \mathrm{O}$

can be modelled by eleven elementary chemical reactions and eight species (cf. J. WARNATZ [42]) or by a more complex or a less complex chemical mechanism.

When the flame model is chosen, the computation of planar travelling waves present the following difficulties : ( $i$ ) existence of a continuum of solutions (in relation with the so-called "cold boundary difficulty"), (ii) the partial differential equations are strongly nonlinear, (iii) the partial differential equations are stiff with disparate length scales, (iv) the system can be very large (depending on the degree of simplification).

Various methods have been proposed for solving these difficulties in a given chemical context. Most of these methods use an unstationary approach (see for instance [6] [8] [9] [17] [23] [24] [32] [36] [37] [39] [45]). A more recent approach is to solve directly the boundary value problem([35] [46]). In the GAMM Workshop (1981) "Numerical methods in laminar flame", some of these methods have been compared on the same chemical mechanism describing the hydrogen-air flame (cf. J. WARNATZ [42]). The participating groups were : DIXON-LEWIS, HEIMERL, JINNO \& FUKUTANI, REITZ, SMOOKE, THIES \& PETERS, WARNATZ, ORAN. 
The aim of the present paper is to solve several mathematical and numerical questions related to stationary and unstationary flames. Most of the results are obtained in the general context of complex chemical and transport models. The corresponding equations are described in Sec. 1 .

In Sec. 2, I give some mathematical properties of the unstationary problem. The main result is the a priori positivity of the mass fractions. This property was known only for a simplified combustion model (cf. CHUEH-CONLEY-SMOLLER [4]). This a priori positivity of solutions is important being a first step for obtaining the stability of numertcal pseudo-unstationary methods.

Sec. 3 is devoted to the mathematical study of the stationary problem. The main result concerns the sensitivity of the flame speed to the computational domain.

Sec. 4 contains a detailled description of a new numerical method for solving the stationary problem. This method combines the use of the pseudo-unstationary approach, the global Newton method and the mesh adaptation.

The efficiency of this method is illustrated in Sec. 5 by the computation of $\mathrm{H}_{2}-\mathrm{O}_{2}-\mathrm{N}_{2}$ flames with complex diffusion and chemical mechanlsms. First, I have carried out the test of the GAMM Workshop [42] (stoichiometric case). The method of Sec. 4 seems faster compared to the other methods and as robust and accurate. Secondly, I present new numerical results concerning the chemical extinction of the $\mathrm{H}_{2}-\mathrm{O}_{2}-\mathrm{N}_{2}$ flame by increase of the inert concentration (this last study was suggested to me by P. CLAVIN).

The results presented in this paper were announced in [33][34].

Acknowledgment : The computations were carried out on the CRAY-1 with the courtesy of the Scientific Council of the "Centre de Calcul Vectoriel pour la Recherche". 


\section{Problem formulation}

1.1. Combustion equations in one-dimensional_space

Let us consider a mixture of $M$ species in one-dimensional space; conservations equations for total mass, enthalpy and masses of each species may be written (see [3] [12] [39] [47] [48]):

$$
\begin{aligned}
& \frac{\partial \rho}{\partial t}+\frac{\partial}{\partial x}(\rho u)=0 \\
& \rho\left(\sum_{i=1}^{M} h_{i}^{\prime} Y_{i}\right)\left(\frac{\partial T}{\partial t}+u \frac{\partial T}{\partial x}\right)-\left(\sum_{i=1}^{M} h_{i}^{\prime} U_{i}\right) \frac{\partial T}{\partial x}-\frac{\partial}{\partial x}\left(\lambda \frac{\partial T}{\partial x}\right)+ \\
& +\sum_{i=1}^{M} h_{i} r_{i}=0 \\
& \rho\left(\frac{\partial Y_{i}}{\partial t}+u \frac{\partial Y_{i}}{\partial x}\right)-\frac{\partial}{\partial x} U_{i}-r_{i}=0,1 \leq i \leq M .
\end{aligned}
$$

The independant variables are the flow velocity $u$, the temperature $T$ and the mass fractions $Y_{i}$ of each species $(1 \leq i \leq M)$.

We shall consider that the diffusion fluxes $U_{i}$ are given by one of the following models:

1) Model recommended by Coffee-Heimer1 [6] (see also [7] [16][40][41])

$$
U_{i}=Y_{i} \rho d_{i} \frac{1}{X_{i}} \frac{\partial X_{i}}{\partial x}+Y_{i} \rho d_{T, i} \frac{1}{T} \frac{\partial}{\partial x} T-Y_{i} U_{C}
$$

where

$$
\begin{aligned}
& \mathrm{X}_{i}=\frac{\mathrm{Y}_{i} / \mathrm{m}_{i}}{\sum_{i=1}^{M} Y_{i} / \mathrm{m}_{i}}, \\
& U_{c}=\sum_{i=1}^{M}\left(Y_{i} \rho d_{i} \frac{1}{X_{i}} \frac{\partial X_{i}}{\partial x}+Y_{i} \rho d_{T, i} \frac{1}{T} \frac{\partial T}{\partial x}\right)
\end{aligned}
$$


2) Approximation of 1) when $\sum_{j=1}^{M} Y_{j} / m_{j} \simeq$ cte :

$$
\begin{aligned}
& U_{i}=\rho d_{i} \frac{\partial Y_{1}}{\partial x}+Y_{i} \rho d_{T, i} \frac{1}{T} \frac{\partial T}{\partial x}-Y_{i} U_{c} \\
& \text { where } U_{c}=\sum_{i=1}^{M}\left(\rho d_{i} \frac{\partial Y_{i}}{\partial x}+Y_{i} \rho d_{T, i} \frac{1}{T} \frac{\partial T}{\partial x}\right)
\end{aligned}
$$

3) The Mth species is in excess :

$$
\begin{aligned}
& U_{i}=\rho d_{i} \frac{\partial Y_{i}}{\partial x}+Y_{i} \rho d_{T, i} \frac{1}{T} \frac{\partial T}{\partial x} \quad 1 \leq i \leq M-1 \\
& U_{M}=-\sum_{i=1}^{M-1} U_{i}
\end{aligned}
$$

Sometimes, we shall take for $U_{i}$ the more general expression :

$$
U_{i}=\sum_{j=1}^{M} \mu_{i j}(T, Y) \frac{\partial Y}{\partial x}+\mu_{i}(T, Y) \frac{\partial T}{\partial x}
$$

In the previous equations, $\rho$ denotes the mass density of the mixture; $\lambda$, the thermal conductivity of the mixture; $h_{1}$, the specific enthalpy of the ith species; $h_{i}^{\prime}=\frac{d_{i}}{d T}\left(=C_{p i}\right)$, the constant pressure heat capacityiof the $i$ th species; $d_{i}, d_{T, i}$, the diffusion coefficients of the $i$ th species in the mixture; $r_{i}$, the mass rate of production of the ith species per unit volume; $m_{i}$, the molar mass of the 1 th species.

The physically admissible domain for $(T, Y)$ is

$$
S=\left\{(T, Y) \in \mathbb{R}^{M+1}, T>0, Y_{i} \geq 0,1 \leq i \leq M, \sum_{i=1}^{M} Y_{i}=1\right\} .
$$

The quantities $m_{i}$ are positive constant ; the quantities $\rho, \lambda, d_{i}$, $d_{T, I}, r_{i}$ are given regular functions of $(T, Y) \in S \quad \supset S$, where

$$
\tilde{S}=\left\{(T, Y) \in \mathbb{R}^{M+1}, T>0, \sum_{i=1}^{M} \cdot Y_{i} / m_{i}>0\right\} ;
$$

$\rho, \lambda, d_{i}$ are positive functions; $h_{i}$ is a function of $T$ alone $(T>0)$; $h_{i}^{\prime}=\frac{d h_{i}}{d T}$ is positive. The production terms $r_{i}$ are obtaines as sums of contributions of all elementary chemical reactions. As a consequence, the functions $r_{i}$ satisfy : 


$$
\begin{aligned}
& \sum_{i=1}^{M} r_{1}(T, Y)=0 \quad \forall(T, Y) \in S \quad \text { (mass conservation) } \\
& r_{i}(T, Y) \geq 0 \quad \forall(T, Y) \in \tilde{S} \quad \text { with } Y \geq 0 \text { and } Y_{1}=0
\end{aligned}
$$

Remark 1.1 :

1) The thermal diffusion terms $\rho Y_{1} d_{T, I} \frac{1}{T} \frac{\partial T}{\partial x}$ which appear in (1.4) are usually negligible, i.e. we can take $d_{T, 1}=0$, possibly except for the light species (cf. J. WARNATZ [4.1] ).

11) In the special case" $d_{T, 1}=0, d_{i}=d \quad \forall i "$, both models $(1.4)_{2}$ and $(1.4)_{3}$ are equivalent to

$$
U_{i}=\rho d \frac{\partial Y_{1}}{\partial \mathbf{x}}
$$

\subsection{Evolution problem in lagrangian coordinates}

The flow velocity u can be eliminated from (1.1)-(1.3) by introducing the lagrangian coordinates $(t, z)$ defined by $\frac{\partial z}{\partial x}=\rho, \frac{\partial z}{\partial t}=-\rho u$. We obtain the following problem $\left(\varepsilon_{k}\right)$, where $k$ refers to the choice of the diffusion fluxes model $(1.4)_{k}$.

$\left(\xi_{k}\right)\left\{\begin{array}{l}\left(\sum_{i=1}^{M} h_{i}^{\prime} Y_{i}\right) \frac{\partial T}{\partial t}-\left(\sum_{i=1}^{M} h_{i}^{\prime} U_{i}\right) \frac{\partial T}{\partial z}-\frac{\partial}{\partial z}\left(\rho \lambda \frac{\partial T}{\partial z}\right)+\sum_{i=1}^{M} \frac{h_{i} r_{i}}{\rho}=0 \\ \frac{\partial Y_{i}}{\partial t}-\frac{\partial}{\partial z} U_{i}-\frac{r_{i}}{\rho}=0,1 \leq i \leq M\end{array}\right.$

\subsection{Trave11 ing_waves}

The travelling waves are the stationary solutions of $(1.1)-(1.4)$ on the spatial domain $(-\infty,+\infty)$; as a result, $(c, T, Y)$ is solution of :

$$
\begin{aligned}
& \rho u=c \text {, unknown constant, } \\
& \left\{c \sum_{i=1}^{M} h_{i}^{\prime} Y_{i}-\sum_{i=1}^{M} h_{i}^{\prime} U_{i}\right\} \frac{d T}{d x}-\frac{d}{d x}\left(\lambda \frac{d T}{d x}\right)+\sum_{i=1}^{M} h_{i} r_{i}=0 \\
& c \frac{d Y}{d x}-\frac{d}{d x} U_{i}-r_{i}=0,1 \leq i \leq M, \\
& \underset{\left.C_{k}\right)}{1 i m} T(x)=T_{u^{\prime}} \underset{x \rightarrow-\infty}{\lim } Y_{i}(x)=Y_{i u}
\end{aligned} .
$$




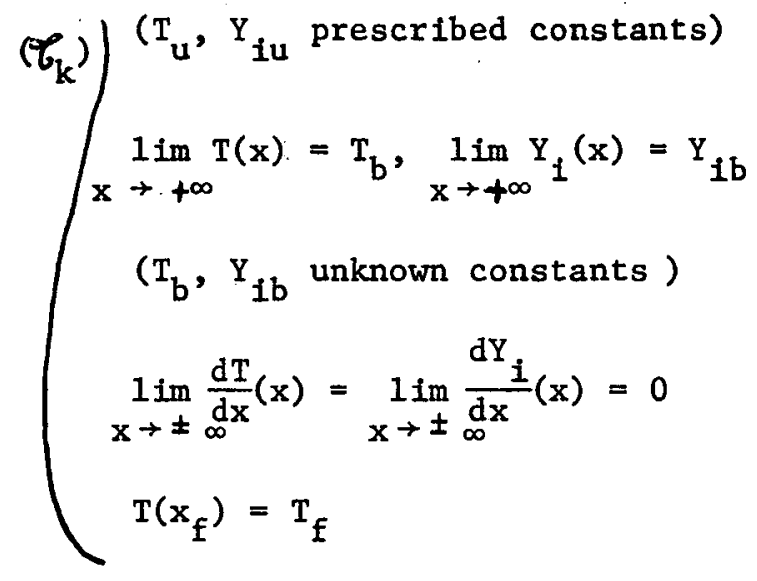

where $x_{f}, T_{f}$ are prescribed constants which fix the flame with respect to the $x$-axis (we could also $f$ ix $Y_{\text {io }}$ instead of $T$ ); the index $k$ of $\left(\mathcal{C}_{k}\right)$ refers to the choice of the diffusion fluxes model $(1.4)_{\mathrm{k}}$.

\section{SOME MATHEMATICAL PROPERTIES OF THE UNSTEADY SOLUTIONS}

During Sec. 2, D denotes a bounded interval of $\mathbb{R}, \tau$ a real positive number, $Q$ is $D \times(0, \tau)$; we call smooth solution of $\left(\&_{k}\right)$ on $Q$ every regular function $(T, Y): Q \rightarrow \tilde{S}$ which satisfies $\left(\varepsilon_{k}\right) \forall(z, t) \in Q$.

In Sec, 2.1 and 2.2, we precise the boundary conditions for which we have enthalpy and mass conservation. In Sec. 2.3 , we prove that $S$ is an invariant region for $\left(\xi_{k}\right)$, i.e. any smooth solution $(T, Y)$ of $\left(\varepsilon_{k}\right)$ with initial values in $S$ satisfies $(T, Y)(z, t) \in S \quad \forall(z, t) \in Q$. This result is also important for computing stationary solutions by a pseudo-unstationary approach.

\subsection{Entha1py conservation}

Proposition 2.1. Let $(T, Y)$ be a smooth solution of $\left(\varepsilon_{k}\right), 1 \leq k \leq 3$, on Q. We suppose that

$$
\frac{\partial T}{\partial z}(z, t)=\frac{\partial Y_{1}}{\partial z}(z, t)=0 \quad \forall(z, t) \epsilon \partial D \times(0, \tau)
$$

Then 


$$
\sum_{i=1}^{M} \int_{D} h_{i}(T(z, t)) Y_{i}(z, t) d z=\sum_{i=1}^{M} \int_{D} h_{i}(T(z, 0)) Y_{I}(z, 0) d z \quad \forall t \in(0, \tau)
$$

Proof : First we observe that

$$
\begin{aligned}
& h_{i}^{\prime}(T(z, t)) \frac{\partial T}{\partial t}=\frac{\partial}{\partial t} h_{i}(T(z, t)), \\
& h_{i}^{\prime}(T(z, t)) \frac{\partial T}{\partial z}=\frac{\partial}{\partial z} h_{i}(T(z, t))
\end{aligned}
$$

We multiply each equation of $(1.8)$ by $h_{1}$ and we add to $(1.7)$. We obtain

$$
\frac{\partial}{\partial t}\left(\sum_{i=1}^{M} h_{i}(T) Y_{i}\right)-\frac{\partial}{\partial z}\left(\sum_{i=1}^{M} h_{i}(T) U_{i}\right)-\frac{\partial}{\partial z}\left(\rho \lambda \frac{\partial T}{\partial z}\right)=0
$$

We integrate (2.3) with respect to $z$ over D. By (2.1), we obtain $(2.2)$

\subsection{Mass conservation}

Proposition 2.3. Let $(T, Y)$ be a smooth solution of $\left(\xi_{k}\right), 1 \leq k \leq 3$, on $Q$. We suppose that

$$
\begin{aligned}
& \sum_{i=1}^{M} Y_{i}(z, 0)=1 \quad \forall z \in D, \\
& \left\{\sum_{i=1}^{M} Y_{i}(z, t)=1 \text { or } \sum_{i=1}^{M} U_{i}(z, t)=0\right\} \quad \forall(z, t) \in \partial D \times(0, \tau)
\end{aligned}
$$

Then

$$
\sum_{i=1}^{M} Y_{i}(z, t)=1 \quad \forall(z, t) \in Q .
$$

Proof : We add the equations of (1.8). By (1.5), we obtain

$$
\frac{\partial}{\partial t}\left(\sum_{i=1}^{M} Y_{i}\right)-\frac{\partial}{\partial z}\left(\sum_{i=1}^{M} U_{i}\right)=0 \text {, on } Q \text {. }
$$

The case $(1.4)_{3}$ is trivial ; in the other cases, we have

$$
\sum_{i=1}^{M} U_{i}=\left(1-\sum_{i=1}^{M} Y_{i}\right) U_{c}
$$


The function $\phi=1-\sum_{i=1}^{M} Y_{i}$ satisfies

$$
\frac{\partial \phi}{\partial t}+\frac{\partial}{\partial z}\left(U_{c} \phi\right)=0 \text { on } Q \text {. }
$$

We multiply by $\phi$ and we integrate in $z$. We obtain

$$
\frac{1}{2} \frac{d}{d t} \int_{D} \phi^{2} d z+\frac{1}{2} \int_{D} \frac{\partial U_{C}}{\partial z} \phi^{2} d z-\frac{1}{2}\left[U_{C} \phi^{2}\right]_{\partial D}=0 .
$$

We have $\phi U_{c}=\sum_{i=1}^{M} U_{i} \cdot$ By $(2.5)$, we obtain

$$
\left[U_{c} \phi^{2}\right]_{\partial D}=\left[\left(\sum_{i=1}^{M} U_{i}\right) \phi\right]_{\partial D}=0 \text {. }
$$

Hence

$$
\frac{1}{2} \frac{d}{d t} \int_{D} \phi^{2} d z=-\frac{1}{2} \int_{D} \frac{\partial U_{C}}{\partial z} \phi^{2} d z
$$

Since $(T, Y)$ is a regular function from $Q$ in $S, U_{c}$ is regular.

Thus, we can write

$$
\frac{d}{d t} \int_{D} \phi^{2} d z s \alpha \int_{D} \phi^{2} d z
$$

with $\alpha=\sup _{(z, t) \in Q}\left|\frac{\partial}{\partial z} U_{c}(z, t)\right|<\infty$

From Gronwall lemma, we obtain

$$
\int_{D} \phi^{2}(z, t) d z \leq \exp (\alpha t) \int_{D} \phi^{2}(z, 0) d z=0
$$

and Prop. 2.2. is proved.

Prop.2.2 shows that $\left(\xi_{k}\right), 1 \leq k \leq 3$, is equivalent with the following problem $\left(\tilde{\xi}_{k}\right)$ :

$$
\left(\tilde{\dot{s}}_{\mathrm{k}}\right)\left\{\begin{array}{l}
\text { equation }(1.7) \\
\text { equations of }(1.8) \text { fox } 1 \leq i \leq M-1 \\
Y_{M}=1-\sum_{i=1}^{M-1} Y_{i}
\end{array}\right.
$$


It is easy to prove that $\left(\tilde{\xi}_{k}\right)$ is elliptic in $z$, 1.e. the diffusion matrix of $\left(\tilde{\varepsilon}_{k}\right)$ 1s regular, whereas $\left(\varepsilon_{k}\right)$ is not elliptic.

Remark 2.1. Without more hypotheses on the coefficients $\mathrm{d}_{1}$, the diffusion matrix of $\left(\tilde{\varepsilon}_{k}\right), k=1,2$, is not always positive definite; for this reason, the existence of smooth solution of $\left(\xi_{k}\right)$ or $\left(\tilde{\xi}_{k}\right)$ is not always guaranteed. In the case $k=3$, the diffusion matrix is positive definite (and diagonal) and the existence of solution is proved (cf.B. LARROUTUROU [20]).

\subsection{Invar fant regions}

We put

$$
\begin{aligned}
& I_{k}=\{1, \ldots, M\} \text { for } 1 \leq k \leq 2 \\
& I_{3}=\{1, \ldots, M-1\}
\end{aligned}
$$

The main result of this section is

Theorem 2.1. Let $(T, Y)$ be a smooth solution of $\left(\varepsilon_{k}\right)$ on $Q, 1 \leq k \leq 3$. We suppose that Then

$$
\begin{aligned}
& Y_{i}(z, 0)>0 \quad \forall z \in D, \forall i \in I_{k}, \\
& \left\{Y_{i}(z, t)>0 \text { or } \frac{\partial Y_{i}}{\partial v}(z, t) \geq 0\right\} \quad \forall(z, t) \in \partial D \times(0, \tau), \forall i \in I_{k}
\end{aligned}
$$

$$
Y_{i}(z, t)>0 \quad \forall(z, t) \in Q, \forall i \in I_{k}
$$

Several authors (WEINBERGER [44], CHUEH-CONLEY-SMOLLER [4 $D$ have given necessar and sufficient conditions for determining the invariant regions of weakly coupled (1) parabolic or elliptic systems. The system $\left(\varepsilon_{k}\right)$ is not weakly coupled; nevertheless; we can adapt the method of proof used by WEINBERGER in [44].

(1) A system of m partial differential equations in m unknown functions is sald "weakly coupled" if the ith equation only contains derivatives of the ith function. 
Proof : Each definition $(1.4)_{k}$ can be rewritten as

$$
U_{i}=Z_{i}(T, Y) \frac{\partial Y_{i}}{\partial z}+Y_{i} F_{i}\left(T, Y, \frac{\partial Y}{\partial z}, \frac{\partial T}{\partial z}\right) \quad i \in I_{k}
$$

where $\tilde{d}_{i}$ and $F$ are smooth functions (we observe that, for $Y_{i}=0$, the system is weakly coupled).

As a consequence, for $i \in I_{k}, Y_{i}$ is solution of

$$
\frac{\partial Y_{i}}{\partial t}-a_{i}(z, t) \frac{\partial^{2} Y_{i}}{\partial z^{2}}+b_{i}(z, t) \frac{\partial Y_{i}}{\partial z}+c_{i}(z, t) Y_{i}=f_{i}\left(z, t, Y_{i}\right)
$$

where $a_{1}, b_{1}, c_{1}$ are regular functions on $Q ; f_{1}$ is defined by

$$
\begin{gathered}
f_{1}(z, t, s)=r_{i}\left(T(z, t), Y_{1}(z, t), \ldots, Y_{1-1}(z, t), s, Y_{i+1}(z, t), \ldots, Y_{M}(z, t)\right) . \\
. \rho(T(z, t), Y(z, t))^{-1}
\end{gathered}
$$

We proceed now by contradiction. Let $t^{*}>0$ such that

$$
\begin{cases}Y_{i}\left(z^{*}, t^{*}\right)=0 & \text { for some } z^{*} \in \bar{D} \text { and some } i \\ Y_{j}(z, t)>0 & \forall(z, t) \times D \times\left(0, t^{*}\right), \forall j\end{cases}
$$

From $(2.10),(1.6)$, we have

$$
f_{1}(z, t, 0) \geq 0 \quad \forall(z, t) \in D \times\left(0, t^{*}\right)
$$

Hence

$$
\frac{\partial Y_{i}}{\partial t}-a_{i}(z, t) \frac{\partial^{2} Y_{i}}{\partial z^{2}}+b_{i}(z, t) \frac{\partial Y_{i}}{\partial z}+c_{i}(z, t) Y_{I} \geq f_{i}\left(z, t, Y_{i}\right)-f(z, t, 0)
$$

We introduce

$$
\mu(z, t)= \begin{cases}\frac{f_{i}\left(z, t, Y_{i}(z, t)\right)-f_{i}(z, t, 0)}{Y_{i}(z, t)} & \text { if } Y_{i}(z, t) \neq 0, \\ 0 & \text { otherwise }\end{cases}
$$

Since $r_{i}$ is a smooth function, $\mu$ is bounded on $D \times(0, \tau)$. 
We finally obtain that $Y_{1}$ satisfies

$$
\frac{\partial Y_{1}}{\partial t}-a_{1}(z, t) \frac{\partial^{2} Y_{i}}{\partial z^{2}}+b_{i}(z, t) \frac{\partial Y_{1}}{\partial z}+\left(c_{i}-\mu\right)(z, t) Y_{1} \geq 0 \quad \forall(z, t) \in D \times\left(0, t^{*}\right)
$$

where $a_{i}, b_{i}, c_{i}$ are smooth, $a_{i}$ is positive, $\mu$ is bounded on $D \times\left(0, t^{*}\right)$. It follows from the maximum principle (cf. PROTTER-WEINBERGER [31]

th. 3.5-3.6) that : (1) if $z^{*} \in D$, then $Y_{1}=0$ on $D \times\left(0, t^{*}\right),(11)$ if $z^{*} \in \partial D$, then $\frac{\partial}{\partial V} Y_{1}<0$. Both cases 1 ) and ii) contradicts (2.7) or (2.8), which proves Theorem 2.1 .

\section{Remarks 2.2.}

1) In the case $k=3$ (but not $k=1$ or 2); theorem 2.1 is also valid with all strịct inequalities replaced by large inequalities (cf.Remark 2.1).

i1) Proposition 2.1 and Theorem 2.1 yield the following a priori bound

$$
\left\{\begin{array}{l}
0 \leq Y_{1}(z, t) \leq 1 \quad \forall(z, t) \in Q, I \in I_{k} \\
\int_{D} T(z, t) d z \leq c
\end{array}\right.
$$

But we have not $L^{\infty}(Q)$ bound on the temperature, except in the case $d_{T, i}=0$ and Lewis numbers $=1$, i.e. $d_{i} \equiv d \equiv \frac{p \lambda}{c_{p 1}} \forall i$.

\section{SOME MATHEMATICAL PROPERTIES OF THE TRAVELLING WAVES}

In Sec. 3.1, we recall the classical enthalpy conservation for travelling waves. We intend to solve $\left(\boldsymbol{C}_{k}\right)$ by ia finite-difference method, so we need to formulate an approximate problem on a bounded domain. In Sec. 3.2, we present an heuristic method for choosing the boundary conditions on a bounded domain and we show that the enthalpy is still conserved. In Sec. 3,3, we give an upper bound of the error due to the truncation of the domain in the case of a single one-step chemical reaction.

\subsection{Enthalpy conservation}

Proposition 3.1. Let $(c, T, Y)$ be a smooth solution of $\left(\mathcal{C}_{k}\right), 1 \leq k \leq 3$, with $c \neq 0$. Then

$$
\sum_{i=1}^{M} h_{i}\left(T_{u}\right) Y_{i u}=\sum_{i=1}^{M} h_{i}\left(T_{b}\right) Y_{i b}
$$


Proof : We multiply each equation of $(1.10)$ by $h_{i}$ and we add to (1.9). We obtain

$$
c \frac{d}{d x}\left(\sum_{i=1}^{M} h_{i} Y_{i}\right)-\frac{d}{d x}\left(\sum_{i=1}^{M} h_{i} U_{i}\right)-\frac{d}{d x}\left(\lambda \frac{d T}{d x}\right)=0
$$

We integrate in $x$. By (1.13), we obtain (3.1).

Remark 3.1. Since $h_{1}$ are strictly increasing functions, it turns out that (3.1) gives a unique value $T_{b}=T_{b}\left(T_{u}, Y_{i u}, Y_{i b}\right)$, which is called the adlabatic flame temperature.

\subsection{Heuristic choice of the boundary condittons}

Let $[a ; b]$ a bounded domain of $\mathbb{R}$ which contains $x_{f}$.

Let $(c, T, Y)$ be a smooth solution of $\left(\mathcal{C}_{k}\right), 1 \leq k \leq 3$. We integrate $(3.2)$ and $(1.10)$ over $(-\infty, a)$; we obtain

$$
\begin{aligned}
& \lambda(a) \frac{d T}{d x}(a)+\sum_{i=1}^{M} h_{i}(T(a)) U_{i}(a)=c \sum_{i=1}^{M}\left(h_{i}(T(a)) Y_{i}(a)-h_{i}\left(T_{u}\right) Y_{i u}\right), \\
& U_{i}(a)=c\left(Y_{i}(a)-Y_{i u}\right)-\int_{-\infty}^{a} Y_{i}(T(x), Y(x)) d x
\end{aligned}
$$

The combination of $(3.3),(3.4)$ gives

$$
\lambda(a) \frac{d T}{d x}(a)=c \sum_{i=1}^{M}\left(h_{i}(T(a))-h_{i}\left(T_{u}\right)\right) Y_{I u}+\sum_{i=1}^{M} h_{i}(T(a)) \int_{-\infty}^{a} r_{i}(T(x), Y(x)) d x
$$

If we suppose now that the reactions terms are negligible on the region $(-\infty, a)$, we obtain

$$
\begin{aligned}
& \lambda(a) \frac{d T}{d x}(a)=c \sum_{i=1}^{M}\left(h_{i}(T(a))-h_{i}\left(T_{u}\right)\right) Y_{i u} \\
& U_{i}(a)=c\left(Y_{i}(a)-Y_{i u}\right)
\end{aligned}
$$

As a result, we shall consider the following problem $\left(\mathcal{C}_{k}^{*}\right)$ on a given bounded domain $[a, b]$ which contains $x_{f}$ and which is large enough : 
$\left(\mathcal{Q}_{\mathrm{k}}^{*}\right)\left\{\begin{array}{l}\text { equations }(1.9),(1.10) \text { on }(a, b), \\ \text { boundary conditions }(3.6),(3.7) \text { for } x=a, \\ \frac{d T}{d x}(b)=\frac{d Y}{d x}(b)=0 \\ T\left(x_{f}\right)=T_{f}\end{array}\right.$

The boundary conditions (3.7), (3.8) (but not.(3.6)) are those used by Smooke-Miller-Kee in [35] (cf. also [21]). Otherwise the reason for which we don't use stmilar left and right boundary conditions is that unburnt quantities $T_{u}, Y_{i u}$ are prescribed, whereas burnt quantities $T_{b}, Y_{i b}$ are unknown.

Proposition 3.2. Let $(c, T, Y)$ be a smooth solution of $\left(\mathcal{C}_{k}^{*}\right), 1 \leq k \leq 3$, with $c \neq 0$. Then

$$
\sum_{i=1}^{M} h_{1}\left(T_{u}\right) Y_{i u}=\sum_{i=1}^{M} h_{i}(T(b)) Y_{i}(b)
$$

Proof. We integrate (3.2) over $(a, b)$; we obtain

$$
\text { c } \sum_{i=1}^{M} h_{i}(T(b)) Y_{i}(b)=c \sum_{i=1}^{M} h_{i}(T(a)) Y_{i}(a)-\sum_{i=1}^{M} h_{i}(T(a)) U_{i}(a)-\lambda(a) \frac{d T}{d x}(0) \text {. }
$$

By $(3.6),(3.7)$, we obtain (3.9).

\subsection{Estimation of the error due to the truncation of the domain}

\subsubsection{One-step_reaction_with Le $=1$.}

In the case of a single one-step reaction with Le $=1$, the problem $(\mathfrak{T})$ reduces to the following scalar equation :

$$
\left\{\begin{array}{l}
-\left(d(u) u^{\prime}\right)^{\prime}+c u^{\prime}=g(u) \\
u(-\infty)=0, u(+\infty)=1, u(0)=0.5
\end{array}\right.
$$

The function $g:[0,1] \rightarrow[0, \infty)$ is supposed to be lipschitzian, differentiable at 0 , and to satisfy $g(0)=g(1)=0, g(s) \neq 0$ for $s \in(0,1)$; the function $d:[0,1](0, \infty)$ is supposed to be continuously differentiable. 
It has been proved that there exist a positive real number $c_{0}$ such that (3.10) has a unique solution for every $c \geq c_{0}$ and no solution for $c$ in the interval $0<c<c_{0}$ (cf. [1] [14][15][38] for $d=1$ and [25] for any d). We shall denote $u_{0}$ the solution corresponding to $c_{0}$. This solution seems to be the only physical one.

Let $(a, b)$ a given bounded domain of $\mathbb{R}$ containing 0 ; the problem $\left(C^{*}\right)$ (with Dirichlet condition for $x=b$ ) reduces to

$$
\left\{\begin{array}{l}
-\left(d(u) u^{\prime}\right)^{\prime}+c u^{\prime}=g(u) \\
d(u(a)) u^{\prime}(a)=c u(a), u(b)=1
\end{array}\right.
$$

Let $a=-b$. Problem (3.11) has a unfque solution $\left(c_{b}, u_{b}\right)$ satisfying $u_{b}(0)=0.5$ (cf. BERESTYCKI et al. [2]) and this solution satisfies (cf. M. MARION [25])

$$
\left(c_{b}, u_{b}\right)+\left(c_{0}, u_{0}\right) \text { for } b \rightarrow+\infty \text {. }
$$

We have obtained the following new result concerning the system ( 3.11 ).

Theorem 3.1. Let $(c, u)$ be a solution of (3.11) with $b=+\infty$. We suppose that

$$
d(0) g^{\prime}(0)<\alpha \equiv \sup _{0<s<u(a)} \frac{d(s) g(s)}{s}<\int_{0}^{1} d(s) g(s) d s
$$

Then

$$
\frac{1}{2}\left(c_{0}+\left(c_{0}^{2}-4 \alpha\right)^{1 / 2}\right) \leq c<c_{0}
$$

Proof. The basic tool is the comparison of ODE's.

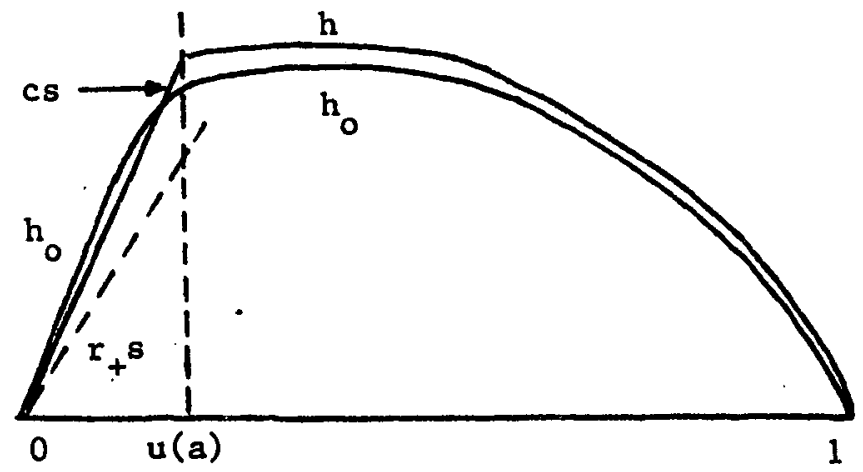

Fig. 3.1. 
The function $h_{0}(s) \equiv d(s) u_{0}^{\prime}\left(u_{0}^{-1}(s)\right)$ is continuous from $[0,1]$ in $[0,+\infty$ ) and satisfies (cf. M. MARION [25]) :

$$
\begin{aligned}
& h_{0}^{\prime}(s)=c_{0}-\frac{d(s) g(s)}{h_{0}(s)}, \\
& h_{0}(0)=h_{0}(1)=0, h_{0}^{\prime}(0)=\frac{1}{2}\left(c_{0}+\left(c_{0}^{2}-4 d(0) g^{\prime}(0)\right)^{1 / 2}\right)
\end{aligned}
$$

Let $\alpha^{\prime}$ be any real number in the interval $\alpha<\alpha^{\prime}<\int_{0}^{1} \mathrm{~d}(\mathrm{~s}) \mathrm{g}(\mathrm{s}) \mathrm{ds}$ i) On one hand, $h_{0}^{\prime}(s)>F\left(s, h_{0}(s)\right)$ for every $s$ in the interval $0<s \leq u(a)$ where $F(s, y) \equiv c_{0}-\alpha \cdot s / y$. We solve the differential equation $y^{\prime}(s)=F(s, y(s))$ with the Initial condition $y(0)=0$. Since $c_{0} \geq\left(2 \int_{0}^{1} k(s) g(s) d s\right)^{1 / 2}$ (cf. [25 J), we obtain the two following
solutions

$$
y_{ \pm}(s)=r_{ \pm} s \text {, with } r_{ \pm}=\frac{1}{2}\left(c_{0} \pm\left(c_{0}^{2}-4 \alpha^{\prime}\right)^{1 / 2}\right) \text {. }
$$

Since $h_{0}^{\prime}(0)=\frac{1}{2}\left(c_{0}+\left(c_{0}^{2}-4 d(0) g^{\prime}(0)\right)^{1 / 2}\right)>y_{ \pm}^{\prime}(0)$, the comparison theorem for ODE gives that

$$
h_{0}(s)>r_{+} s \text { for } 0<s \leq u(a)
$$

ii) On the other hand, we know (cf $[25]$ ) that $c<c_{0}$ and that the function $h(s)=d(s) u^{\prime}\left(u^{-1}(s)\right)$ satisfies

$$
h(s)>h_{0}(s) \text { for } u(a) \leq s<1
$$

By (3.15), (3.16), we obtain (cf. Fig. 3.1)

$$
h(u(a))=c u(a)>h_{0}(u(a))>r_{+} u(a)
$$

We take $\alpha^{\prime}+\alpha$ and we obtain (3.13).

\section{Remark 3.2.}

1) In the case $g^{\prime}(0)=0$, the first inequality of (3.12) is always satisfied and the second one is satisfied when $u(a)$ is small enough. Moreover, the left term of (3.13) converges to $c_{0}$ when $u(a) \rightarrow 0$. ii) The case $k(s) \equiv c t e, g(s)<s g^{\prime}(0)$, studied by KOLMOGOROFFPETROVSKY-PISCOUNOFF [18], never satisfies (3.12). 
b

\subsubsection{One step_reaction_wtth_Le $\geq 1$.}

In the case of one-step reaction with Le $z 1$, the problem $(\mathcal{\&})$ reduces to the following system $(\lambda=1 / \mathrm{Le})$

$$
\left\{\begin{array}{l}
-u^{\prime \prime}+c u^{\prime}=f(u) v \\
-\lambda v^{\prime \prime}+c v^{\prime}=-f(u) v \\
u(-\infty)=0, u(+\infty)=1 \\
v(-\infty)=1, v(+\infty)=0
\end{array}\right.
$$

where $f$ is a $c^{1}$ function: $[0,1] \rightarrow[0, \infty)$ with $f(0)=0$ and $f(s) \neq 0$ for $8 \neq 0$.

We consider the following problem on the half-1ine $(0, \infty)$ :

$$
\left\{\begin{array}{l}
-u^{\prime \prime}+c u^{\prime}=f(u) v \\
-\lambda v^{\prime \prime}+c v^{\prime}=-f(u) v \\
-u^{\prime}(0)+c u(0)=0, u(+\infty)=1 \\
-\lambda v^{\prime}(0)+c(v(0)-1)=0, v(+\infty)=1
\end{array}\right.
$$

As in the scalar case, there exists $c_{0}>0$ such that (3.17) has a solution If and only if $c \geq c_{0}$ (cf. $[22][26]$ ).

We obtain the following new result

Theorem 3.2. Let $(c, u, v)$ be a solution of (3.18). We suppose that

$$
f^{\prime}(0)<\alpha \equiv \frac{1}{\lambda} \sup _{0<s<u(a)} \frac{f(s)(1-s)}{s}<\int_{0}^{1} f(s)(1-s) d s
$$

Then

$$
\frac{1}{2}\left(c_{0}+\left(c_{0}^{2}-4 \alpha\right)^{1 / 2}\right) \leq c<c_{0} .
$$

Proof : The function $h_{0}(s)=u_{0}^{\prime}\left(u_{0}^{-1}(s)\right)$ satisfies (cf. [26])

$$
\begin{aligned}
& h_{0}^{\prime}(s)=c_{0}-\frac{v_{0}\left(u_{0}^{-1}(s)\right) f(s)}{h_{0}(s)}, \\
& h_{0}(0)=h_{0}(1)=0, h_{0}^{\prime}(0)=\frac{1}{2}\left(c_{0}+\left(c_{0}-4 f^{\prime}(0)\right)^{1 / 2}\right)
\end{aligned}
$$


Let $\alpha^{\prime}$ be any real number in the interval $\alpha<\alpha^{\prime} \leqslant \int_{0}^{1} f(s)(1-s) d s$.

1) On one hand, the function $v_{0}$ satisfies (cf. [2] [26])

$$
1-u_{0}(x) \leq v_{0}(x) \leq \frac{1}{\lambda}\left(1-u_{0}(x)\right)
$$

As a consequence, $h_{0}^{\prime}(s)>F\left(s, h_{0}(s)\right)$ where $F(s, y)=c_{0}-\alpha^{\prime} s / y$. We obtain as in Theorem 3.1 that

$$
h_{0}(s)>r_{+} s \text { for } 0<s \leq u(a)
$$

where $r_{+}=\frac{1}{2}\left(c_{0}+\left(c_{0}^{2}-4 \alpha^{\prime}\right)^{1 / 2}\right)$

ii) On the other hand, since $0<\lambda<1$, we still have (cf. [26]) c $<c_{\text {o }}$ and

$$
h(s)=u^{\prime}\left(u^{-1}(s)\right)>h_{0}(s) \text { for } u(a) \leq s<1
$$

By (3.22), (3.23), we obtain (3.21).

\section{NUMERICAL METHOD FOR COMPUTING TRAVELLING WAVES}

We describe the main aspects of our method : use of a pseudounstationary approach ( $\mathrm{Sec}, 4.1$ ) and use of adaptive gridding (Sec. 4.2).

\subsection{Pseudo-unstationary approach}

The solution of $\left(\mathcal{C}_{k}^{*}\right)$ on a given interval $[a, b]$ will be computed by the pseudo-unstationary scheme :

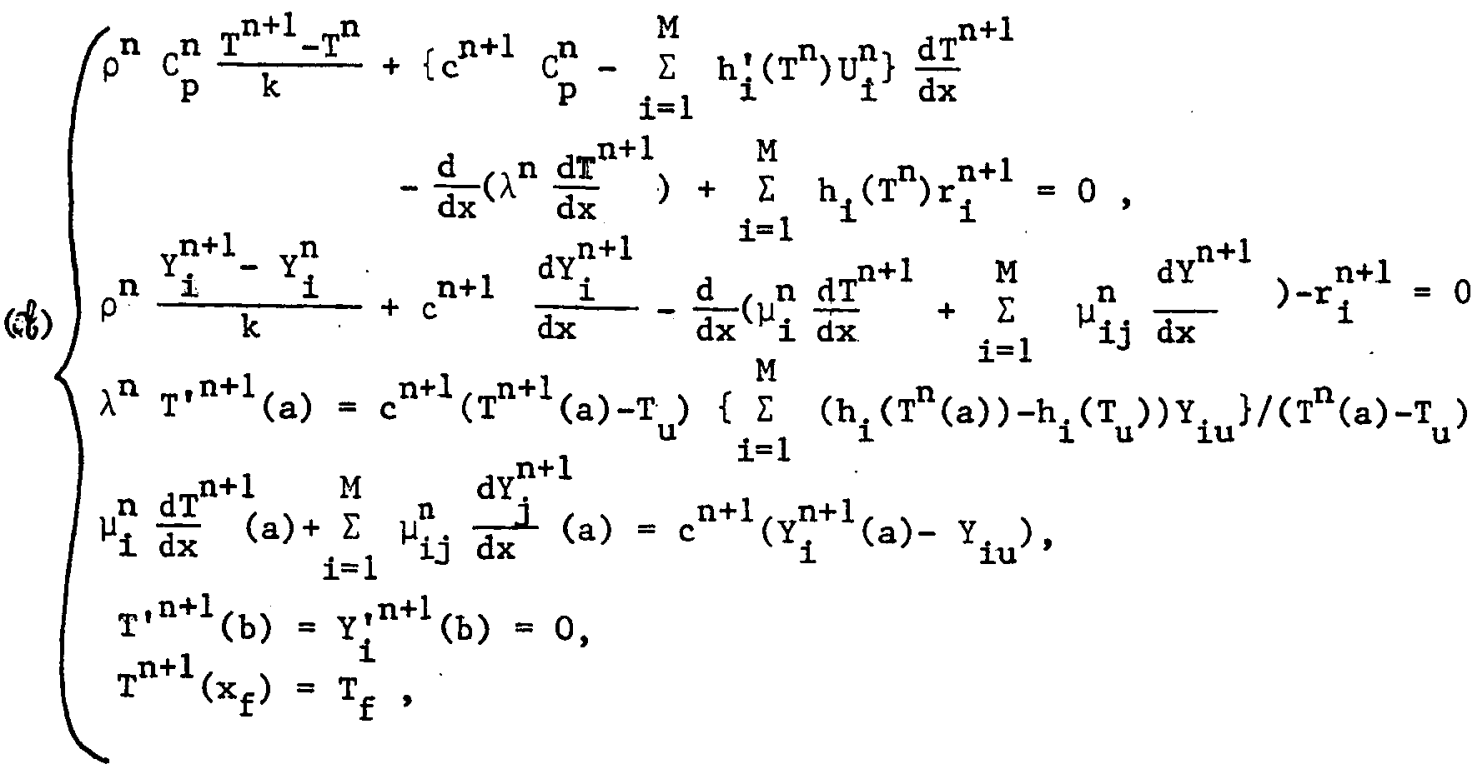


where

$$
\begin{aligned}
& c_{p}^{n}=\sum_{i=1}^{M} h_{i}^{\prime}\left(T^{n}\right) Y_{i}^{n}, \\
& u_{1}^{n}=\mu_{i}^{n} \frac{d T^{n}}{d x}+\sum_{j=1}^{M} \mu_{i j}^{n} \frac{d Y_{j}^{n}}{d x}, \\
& r_{i}^{n+1}=r_{1}\left(T^{n+1}, Y^{n+1}\right), \lambda^{n}=\lambda\left(T^{n}, Y^{n}\right), \mu_{i j}^{n}=\mu_{1 j}\left(T^{n}, Y^{n}\right)
\end{aligned}
$$

Remark 4.1. The system of partial differential equations derived from

$(Q)$ by substituting $\left(\frac{T^{n+1}-T^{n}}{k} ; \frac{Y_{t}^{n+1}-Y_{1}^{n}}{k}\right)$ by $\left(\frac{\partial T}{\partial t}, \frac{\partial Y}{\partial t}\right)$ is a vartant reading of problem $(\varepsilon)$. It can be shown, by the method of proof of Theorem 3.1, that the region $Y_{1}>0$ is invariant for this system.

\section{Space discretization}

Let $\mathcal{Y}=\left\{a=x_{0}<x_{1}<\ldots<x_{N}=b\right\}$ be a mesh of $[a, b]$. Let $P_{1}$ be the space of polynomfals of one vartable of degree less or equal to one and let $V(f)$ be the space

$$
v(\varphi)=\left\{\phi \in c^{0}\left([a, b] ;\left.\phi\right|_{\left[x_{j}, x_{j+1}\right]} \in P_{1}, 0 \leq j \leq N-1\right\}\right.
$$

The computations presented in this paper are obtained by looking for a solution $(C, T, Y)$ in the space $\mathbb{R} \times V(\varphi)^{M+1}$ and by making use of the central differences both for second and first order derlvatives. The functions $h_{1}^{\prime}(T(x))$ is approximated by the plecewise constant function $\delta h_{1}$ given on each interval $\left[x_{j}, x_{j+1}\right]$ by

$$
\delta h_{i}(T(x))= \begin{cases}\frac{h_{i}\left(T\left(x_{j+1}\right)-h_{1}\left(T\left(x_{j}\right)\right)\right.}{T\left(x_{j+1}\right)-T\left(x_{j}\right)} & \text { if } T\left(x_{j}\right) \neq T\left(x_{j+1}\right), \\ h_{i}^{\prime}\left(T\left(x_{j}\right)\right) & \text { otherwise. }\end{cases}
$$

With this choice of approximation, every approximate stationary solution $(c, T, Y)$ satisfies the enthalpy equality :

$$
\sum_{i=1}^{M} h_{i}(T(b)) Y_{i}(b)=\sum_{i=1}^{M} h_{i}\left(T_{u}\right) Y_{i u}
$$


Numerical comparisons between centered and various uncentered first differences are in progress and will be reported by GHILANI (thesis in preparation).

\section{Solution of the discrete problem}

The solution $\left(c^{n+1}, T^{n+1}, Y^{n+1}\right)$ of $(U)$ is computed by a global Newton method, which gives the following organigram :

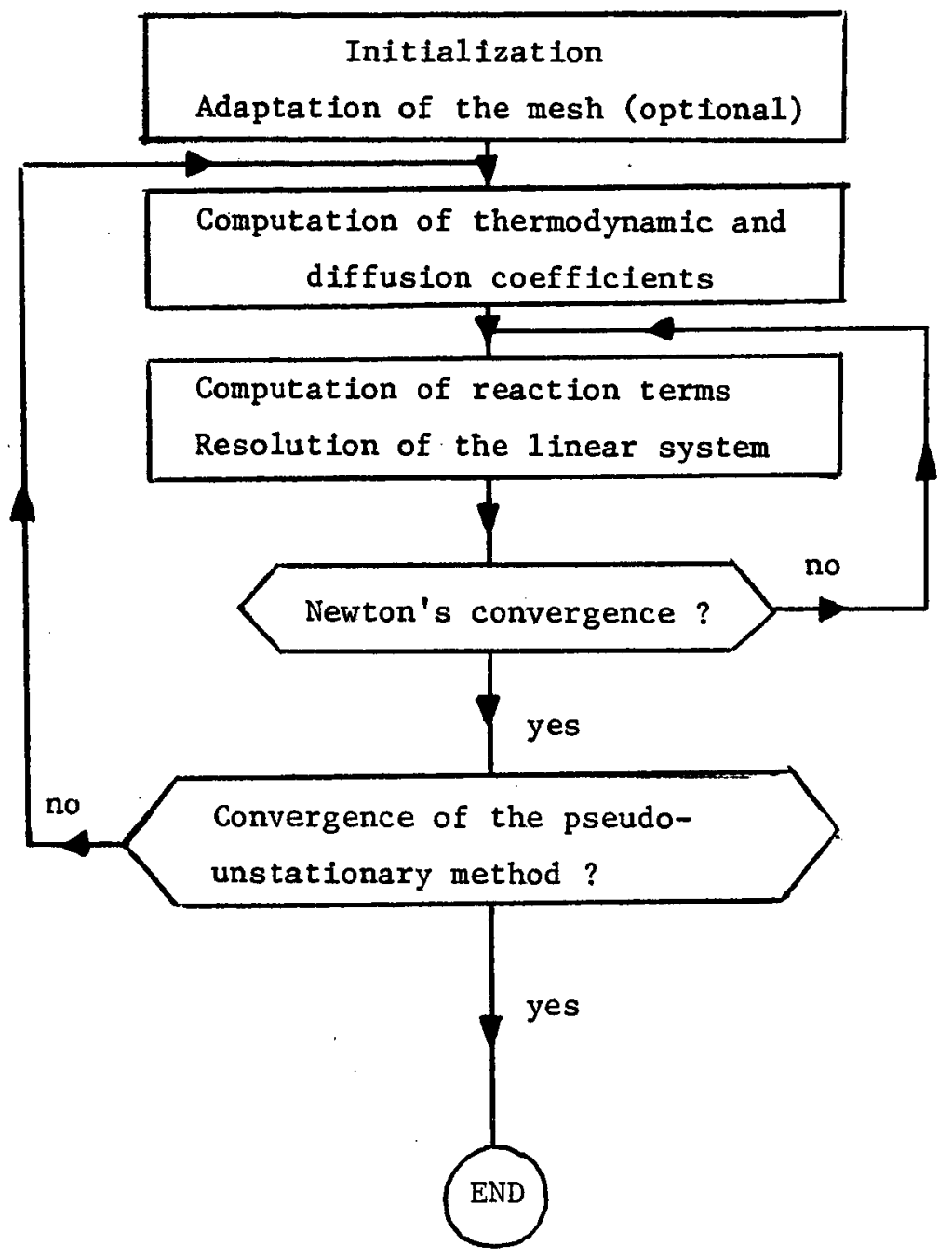


The pseudo-unstationary loop is the external loop; the Newton's loop is the inner loop. The thermodynamic and diffusion coefficients, which are costly to compute and not strongly nonlinear, are explicit in time, so that they are computed only once in an external loop. Since reaction terms are strongly nonlinear, they are computed implicitly.

\section{Adaptation of the time-step $k$}

The time-step $k$ is automatically adjusted according to the rate of convergence of Newton's method :

if convergence in less than ITMIN iterations, $k$ is multiplied by 2 if no convergence after ITMAX iteration, $k$ is multiplied by 0.3 and we restart Newton's 1terations.

Typical values for ITMIN, ITMAX are ITMIN $=4$, ITMAX $=6$.

\section{Linear algebra}

Each Newton's iteration consists in solving a linear system which has the following structure :

$$
\begin{aligned}
& k z+c b_{1}=b_{2} \\
& z_{f}=T_{f}
\end{aligned}
$$

where $\mathrm{K}$ is a block-tridiagonal matrix, $\mathrm{b}_{1}, \mathrm{~b}_{2}$ two vectors. The global matrix for (4.1) is no more block-tridiagonal. In order to keep the block-tridiagonal structure (which is useful for the vectortzation), we solve $(4.1)$ as

$$
z=k^{-1} b_{2}+c k^{-1} b_{1}, z_{i_{f}}=T_{f},
$$

1.e. we factorize $\mathrm{K}$ by Gauss method, we solve two linear systems $\mathrm{K} z_{1}=b_{1}, \mathrm{~K} \mathrm{z}_{2}=\mathrm{b}_{2}$ (negligible cost) and finally we determine $z=z_{1}+c z_{2}$ by the condition $z_{i_{f}}=T_{f}$.

\section{Initialization}

Two kinds of computations are done : (1) computation of a solution of $(\mathcal{T})$ with given values of all the (physical and numerical) parameters 
(ii) the study of the variation of the solution of $(\mathscr{C})$ as a function of some parameter.

In the case (i), we use the following initialization :

$$
\begin{aligned}
& T_{o}(x)=\left\{\begin{array}{l}
T_{u}+\left(T^{*}-T_{u}\right) \exp \left(x-x^{*}\right) a \leq x \leq x^{*} \\
T_{b}+\left(T^{*}-T_{b}\right) \exp \left(x^{*}-x\right) x^{\star} \leq x \leq b
\end{array}\right. \\
& Y_{i}(x)=\left\{\begin{array}{l}
Y_{i u}+\left(Y_{i}^{*}-Y_{i u}\right) \exp \left(x-x^{*}\right) a \leq x \leq x^{*} \\
Y_{i b}+\left(Y_{i}^{*}-Y_{i b}\right) \exp \left(x^{*}-x\right) x^{*} \leq x \leq b
\end{array}\right.
\end{aligned}
$$

where $T^{\star}, T_{b}, Y_{1}^{*}, Y_{1 b}$ are initial values that have to be given; the position $x^{*}$ is determined by

$$
T\left(x_{f}\right)=T_{f}
$$

In the case (ii), we use a pieviously computed solution as initial guess for the next computation, i.e. we use a continuation method.

\subsection{Adaptive mesh generation}

When using the continuation method, we adapt the mesh to the initialization. The method for doing this is to equidistribute some weight-function (see for instance [10][11][13][17][19][28]). Hereafter, we give the function that we have used.

Let $\left\{\mathrm{x}_{0}, \ldots, \mathrm{x}_{\mathrm{N}}\right\}$ be any subdivision of $[\mathrm{a}, \mathrm{b}]$ and let $U \in V(\varphi) \mathrm{M}$, $M \geq 1$. We put $I=\left\{i, 1 \leq i \leq M\right.$, s.t. $\left.U_{i}^{\prime} \neq 0\right\}$. We suppose that $I \neq \emptyset$.

We define a function $\Phi_{U}$ that we call (absolute) total variation of $U$ on $(a, t)$ :

$$
\Phi_{U}(t)=\int_{a}^{t} \max _{i \in I} \frac{\left|U_{i}^{\prime}(s)\right|}{\max _{\tau \in(a, b)} U_{i}(\tau)-\min _{\tau \in(a, b)} U_{i}(\tau)} d s
$$

For $M=1, \Phi_{U}$ is the classical total variation of $U /(\max U-\min U)$. 
We observe that $\Phi_{U} \in V(\mathscr{Y})$ and $\Phi_{U}$ is nondecreasing. As a consequence, we can define an equidistributed mesh $\{\tilde{x}\}$ of $\tilde{N}+1$ points, $\tilde{N}$ arbitrary, by

$$
\left\{\begin{array}{l}
\tilde{x}_{0}=a \\
\Phi_{U}\left(\tilde{x}_{j+1}\right)=\Phi_{U}\left(\tilde{x}_{j}\right)+\frac{\Phi_{U}(b)}{\tilde{N}}, 0 \leq j \leq \tilde{N}
\end{array}\right.
$$

The new function $U{ }^{\prime}$ is defined by linear interpolation of $U$ on the new mesh.

Since $\Phi_{U} \in V(\varphi)$, the effective computation of $\{\tilde{x}\}$ by $(4.2)$ is very easy. The number of elementary operations for computing $(\tilde{x}, \tilde{U})$ from $(x, U)$ is $0(\max (M N, M \tilde{N}))$.

The number $\Phi_{U}(b)$ is an indication of the complexity of the vector function U. It's easy to prove that :

Proposition 4.1. For every $\mathscr{S}$ and $U \in V(\mathscr{\varphi})$ (with $I \neq \emptyset$ ), we have i) $1 \leq \Phi_{U}(b) \leq N$

ii) $\Phi_{U}(b)=1 \Leftrightarrow U_{1}$ are monotone and $U_{i}(t)-U_{i}(a)$ are proportional for every $1,1 \leq i \leq M$.

We can also define a relative total variation of $U$ by computing $\Phi_{V}$ with $V=\left(\log U_{1}, \ldots, \log U_{M}\right)$. In the present computations, we take the total varlation $\Phi_{W}$ corresponding to

$$
W=\left(T, Y_{1}, \ldots, Y_{M}, \log T, \log Y_{1}, \ldots, \log Y_{M}\right) \text {. }
$$

\section{NUMERICAL RESULTS}

We have tested the algorithm discussed above on several typical problems. One of them is the case of the scalar equation (3.10) with such a choice of the function $g$. that the exact solution is known (example : $g(s)=2 s^{2}(1-s)$ ); the corresponding numerical results will be reported by $M$. GHILANI in his thesis. In this section, we test the method on the determination of hydrogen-oxygen-nitrogen flames with a complete reaction mechanism and a realistic transport model. First, results concern the stoichfometric hydrogen-air case (test problem $B$ 
of GAMM Workshop [42]) ; then we present a calculation which displays a chemical extinction when the concentration of inert is increased.

\subsection{Chemical and transport models}

\subsubsection{Reaction mechanism}

For the computation 5.2 , we use the reaction mechanism of the test problem B (table II) of [42]; for the computation 5.3, we use the following reaction mechanism (for reference, see [42] [43]).

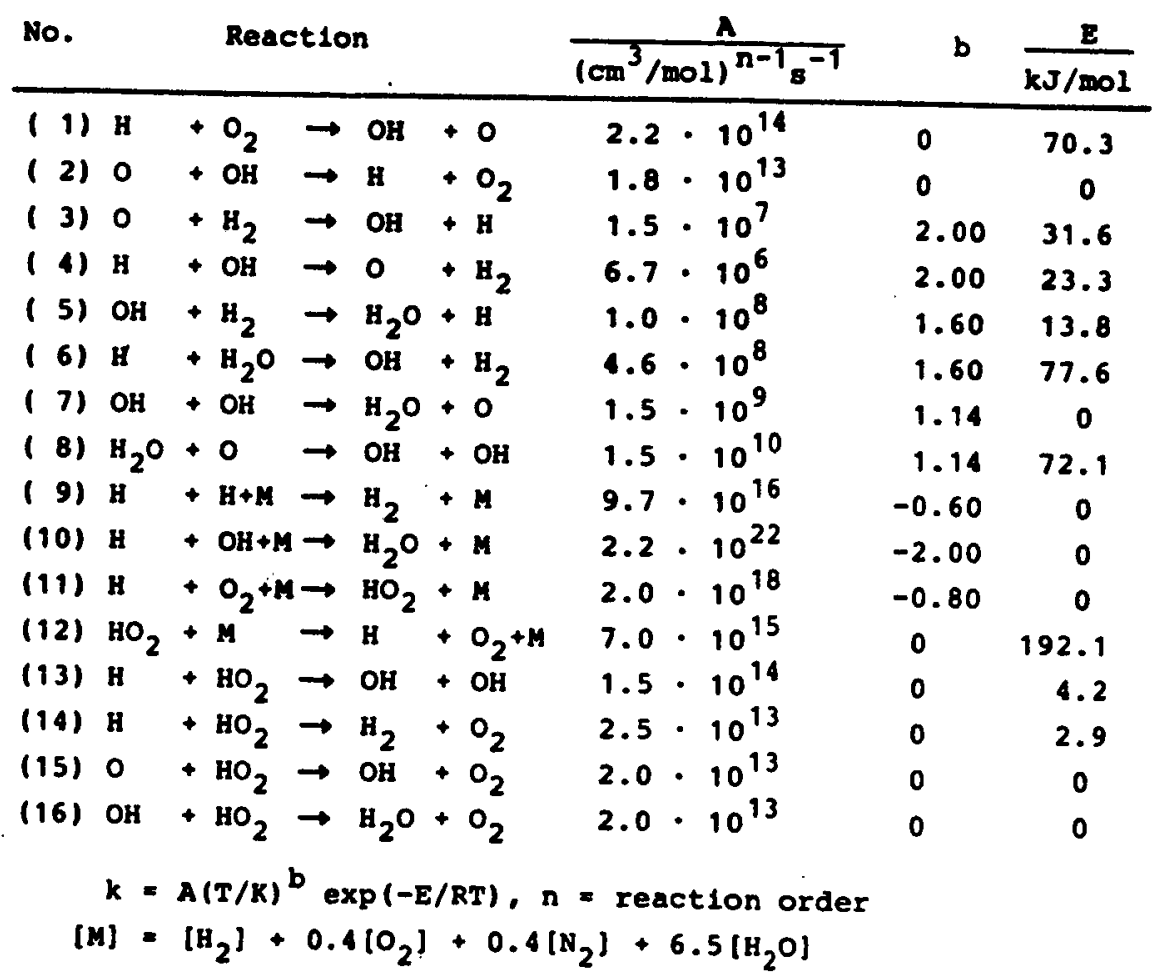

\section{Table I}

\subsubsection{Transport model}

The diffusion coefficient of the species $i$ in the mixture is determined by the formula (cf. [ 6] [7 ] [16])

$$
D_{i}(T, Y)=\frac{1-Y_{i}}{\sum_{j \neq i} X_{i} / D_{i j}(T)}
$$


where the binary diffusion coefficients $D_{i j}(T)$ are given in terms of pressure, temperature and thermodynamic parameters of the species (cf. [16]). We take the thermal diffusion coefficients $d_{T, 1} \equiv 0$. Two options are used for the diffusion flux : either $(1.4)_{2}$ or $(1.4)_{3}$. The conductivity of the mixture is computed by (cf. [16] [27])

$$
\lambda(T, Y)=\frac{1}{2}\left(\sum_{i=1}^{M} x_{i} \lambda_{i}(T)+\frac{1}{\sum_{i=1}^{M} x_{i} / \lambda_{i}(T)}\right)
$$

\subsection{Numerical results for stoichiometric hydrogen-air mixture}

First numerical results concern the stolchiometric hydrogen-air flame, 1.e.

$$
\begin{aligned}
& \mathrm{T}_{\mathrm{u}}=298 \mathrm{~K},\left[\mathrm{H}_{2}\right]_{\mathrm{u}}=2\left[\mathrm{O}_{2}\right]_{\mathrm{u}},\left[\mathrm{N}_{2}\right]_{\mathrm{u}}=4\left[\mathrm{O}_{2}\right]_{\mathrm{u}}, \\
& {[\mathrm{OH}]_{u}=[\mathrm{H}]_{\mathrm{u}}=\left[\mathrm{HO}_{2}\right]_{\mathrm{u}}=\left[\mathrm{H}_{2}\right]_{\mathrm{u}}=0 .}
\end{aligned}
$$

The computation is performed with the following parameters : the length of the domain is $\mathrm{L}=500 \mathrm{~mm} ; \mathrm{x}_{\mathrm{f}}=0$ and $\mathrm{T}_{\mathrm{f}}=299 \mathrm{~K} ; \mathrm{k}_{\mathrm{o}}=10^{-3} \mathrm{~ms}$; the values for the inftialization are listed in Table II ; the mesh has 70 points, given in Table III.

Some computed values are given in Table IV and Fig. 5.1. These results are in good agreement with those reported in [42] and the CPU time seems shorter.

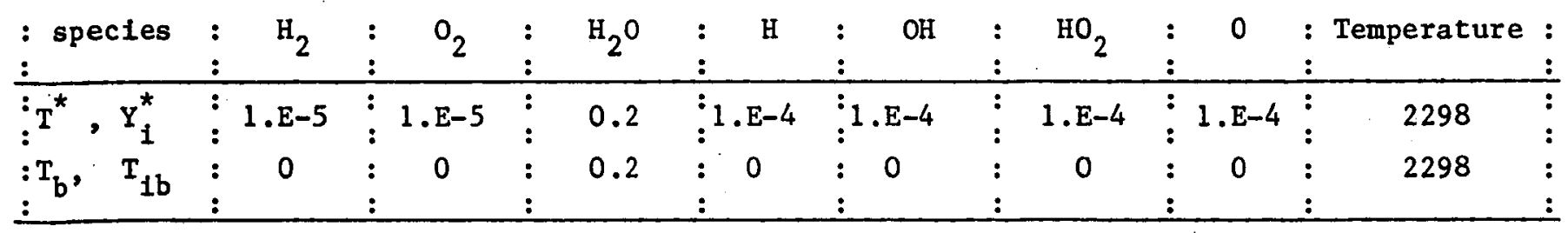

Table II

Values for the initialization 


$\begin{array}{lllllll}0 . & 0.005 & 0.01 & 0.02 & 0.03 & 0.04 & 0.05 \\ 0.06 & 0.07 & 0.08 & 0.09 & 0.10 & 0.11 & 0.12 \\ 0.13 & 0.14 & 0.15 & 0.16 & 0.17 & 0.18 & 0.19 \\ 0.20 & 0.21 & 0.22 & 0.23 & 0.245 & 0.26 & 0.28 \\ 0.30 & 0.32 & 0.35 & 0.36 & 0.38 & 0.40 & 0.42 \\ 0.44 & 0.46 & 0.48 & 0.50 & 0.52 & 0.54 & 0.56 \\ 0.58 & 0.60 & 0.62 & 0.64 & 0.66 & 0.68 & 0.70 \\ 0.75 & 0.80 & 0.85 & 0.90 & 1.0 & 1.2 & 1.4 \\ 1.6 & 1.8 & 2 & 2.5 & 3 & 4 & 5 \\ 8 & 15 & 30 & 50 & 100 & 200 & 500\end{array}$

Table III

Mesh ( $x$ in $\mathrm{mm}$ )

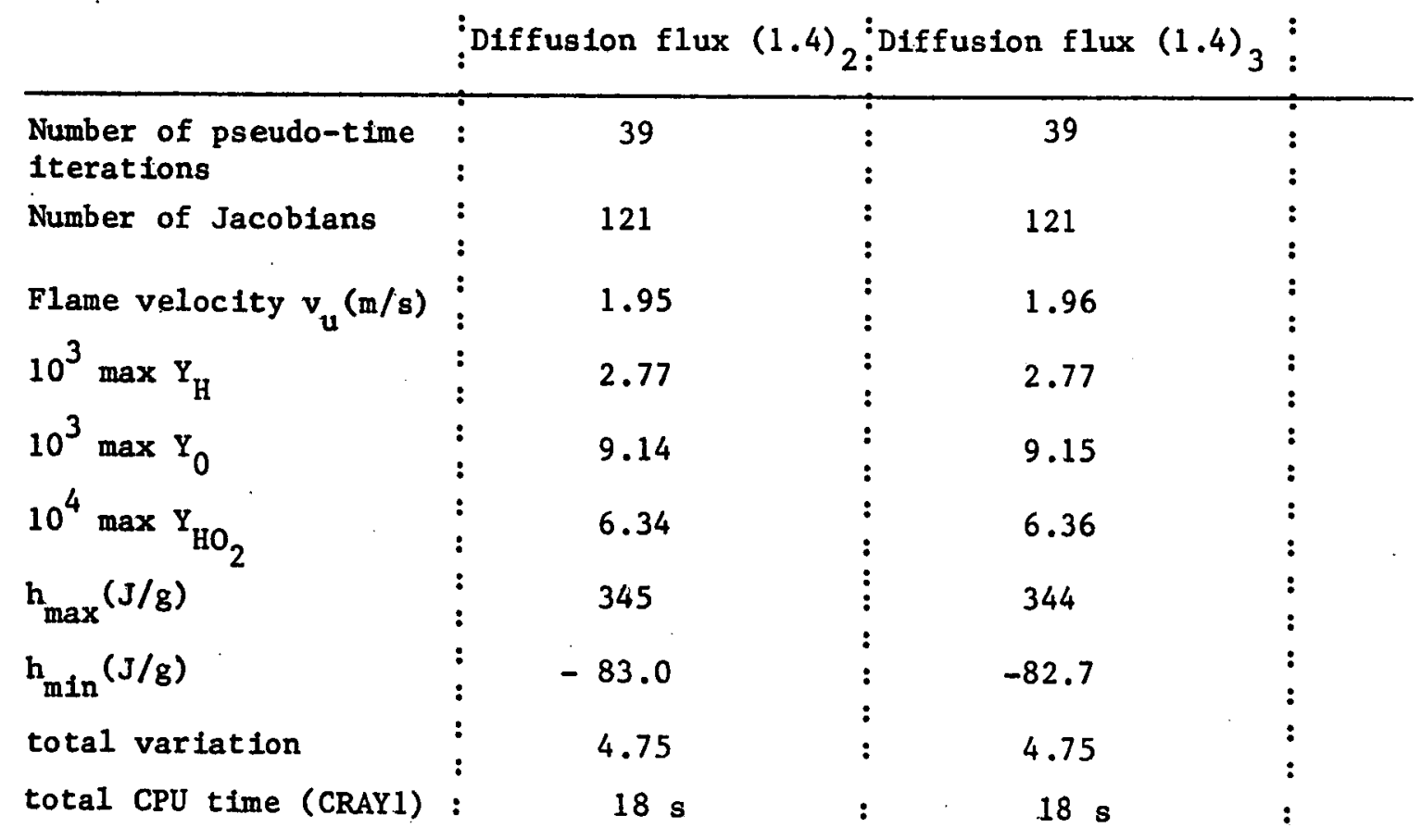




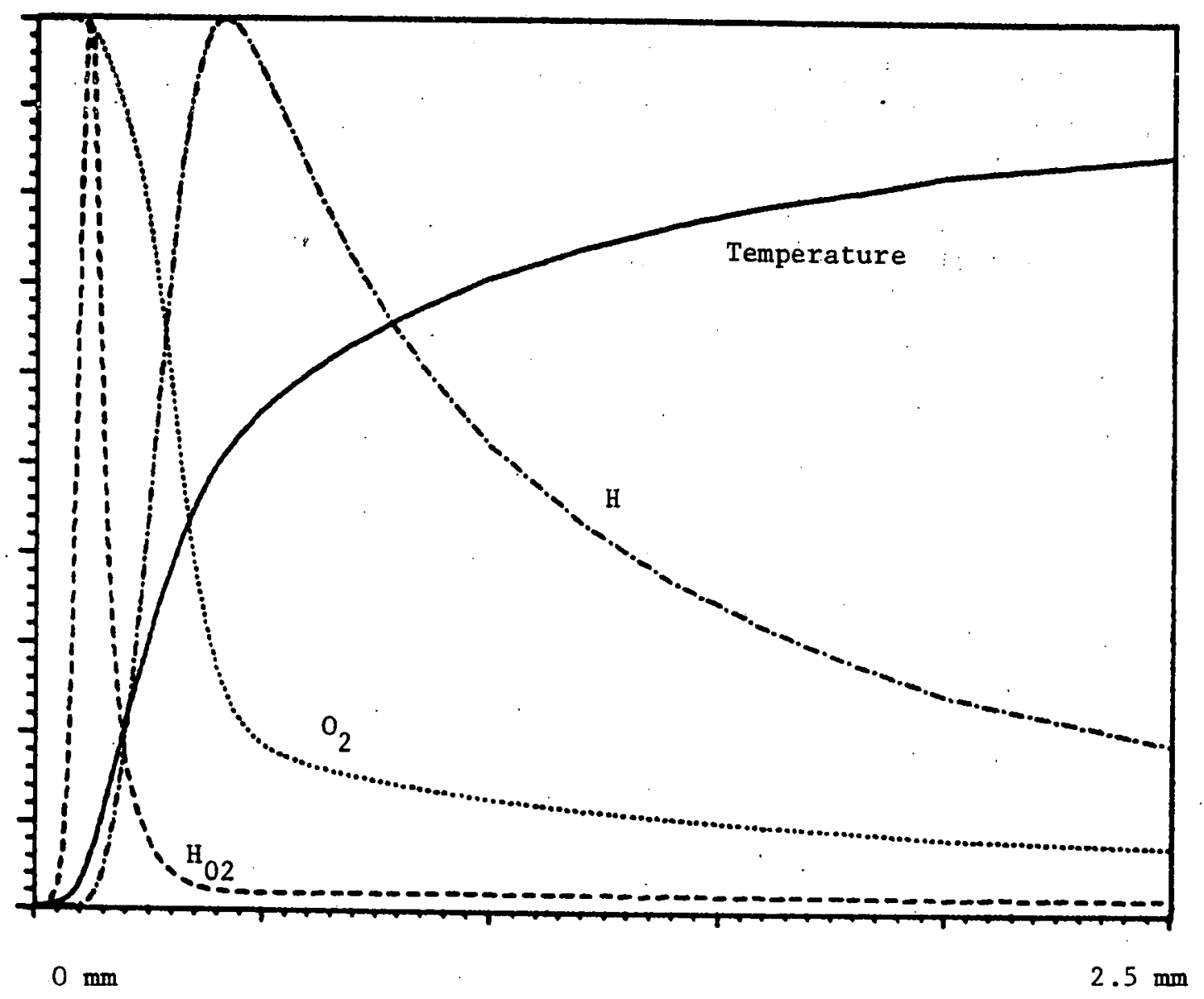

Figure 5.1.

Computed temperature and species profiles

in the stoichiometric case:

Remarks 5.1.

1) The computing time can be reduced by using the same Jacobian for $p$ iterations (modified Newton method). For $p=3$, which seems the best value for the case studied here, we obtain the convergence with : Number of pseudo-time iterations $=25$, Number of jacobians $=59$, CPU time $=13 \mathrm{~s}$.

i1) A sufficient accuracy can be obtained with only half the mesh points. The corresponding computing time is divided by two. 


\subsection{Chemical extinction by increase of the nitrogen concentration}

The chemical extinction of the $\mathrm{H}_{2}-\mathrm{O}_{2}-\mathrm{N}_{2}$ flame by increase of the inert concentration has been established analytically by several authors (LINAN; PETERS; CLAVIN, NICOLI \& PELCE) (cf. [ 5][29] [30]), in the context of a simplified chemical mechanism. Hereafter, we present a numerical study of this question for the realistic chemical mechanism given in Sec. 5.1. (this study was suggested to me by P. CLAVIN). The composition of the fresh mixture is now $\left[\mathrm{H}_{2}\right] /\left[\mathrm{O}_{2}\right]=3,\left[\mathrm{~N}_{2}\right] /\left[\mathrm{O}_{2}\right] \lambda$, where $\lambda$ is a parameter $\geq 4$.

We use a continuation procedure (with respect to $\lambda$ ) : the solution of the governing equations for a given value of $\lambda$ is used as inftialization for the next value of $\lambda$; at the beginning of each computation, the mesh is automatically adapted according to the method described in Sec.4.2 In proportion as $\lambda$ is increased, the flame speed decreases towards zero and the choice of $\left(x_{f}, T_{f}\right)$ becomes crucial.

Results of these computations are reported in Fig. 5.2 - Fig. 5.3. They show a chemical extinction for $\quad\left[\mathrm{N}_{2} y\left[\mathrm{O}_{2}\right] \simeq 21, \mathrm{~T}_{\mathrm{b}} \simeq 947 \mathrm{~K}\right.$.

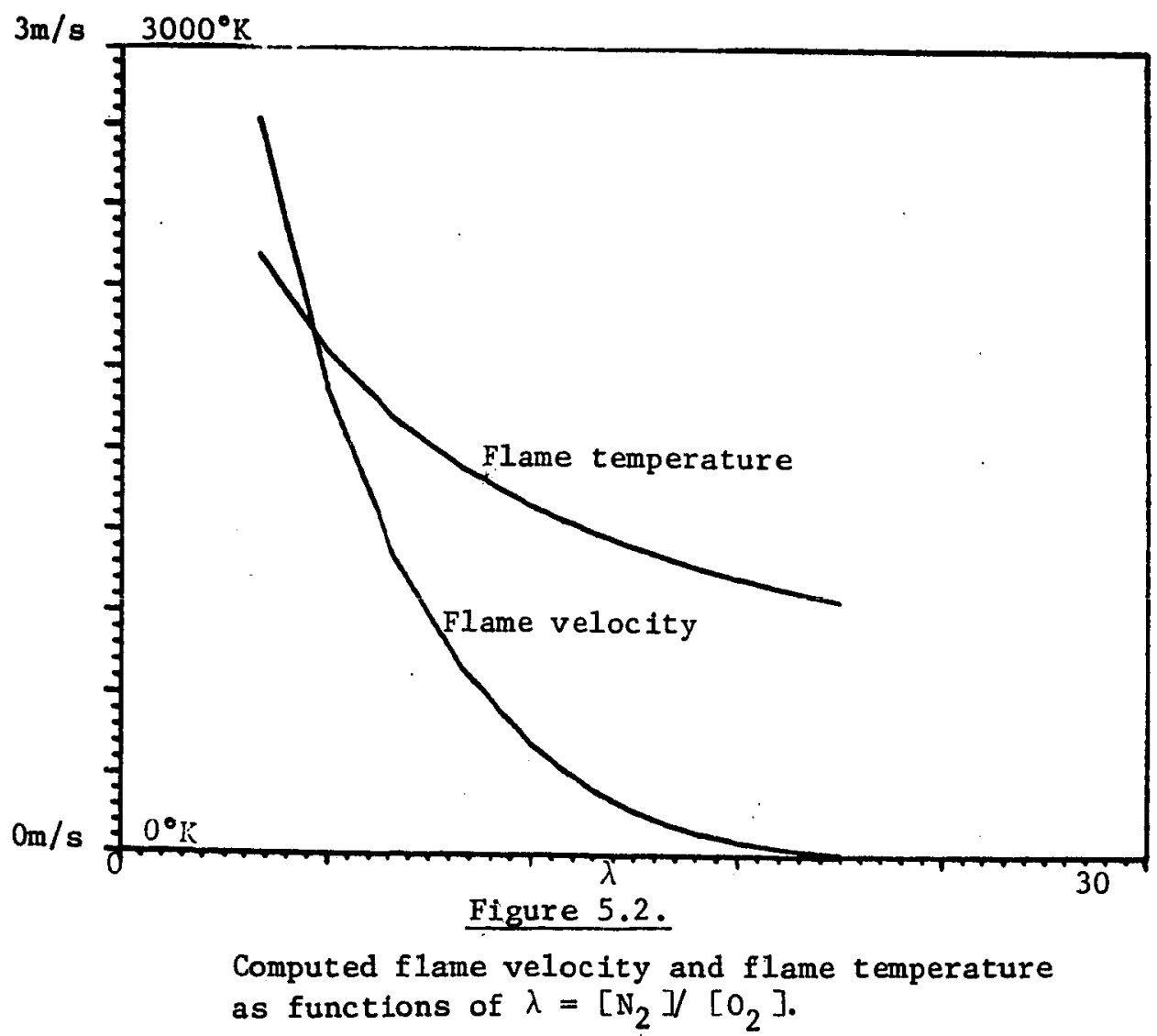




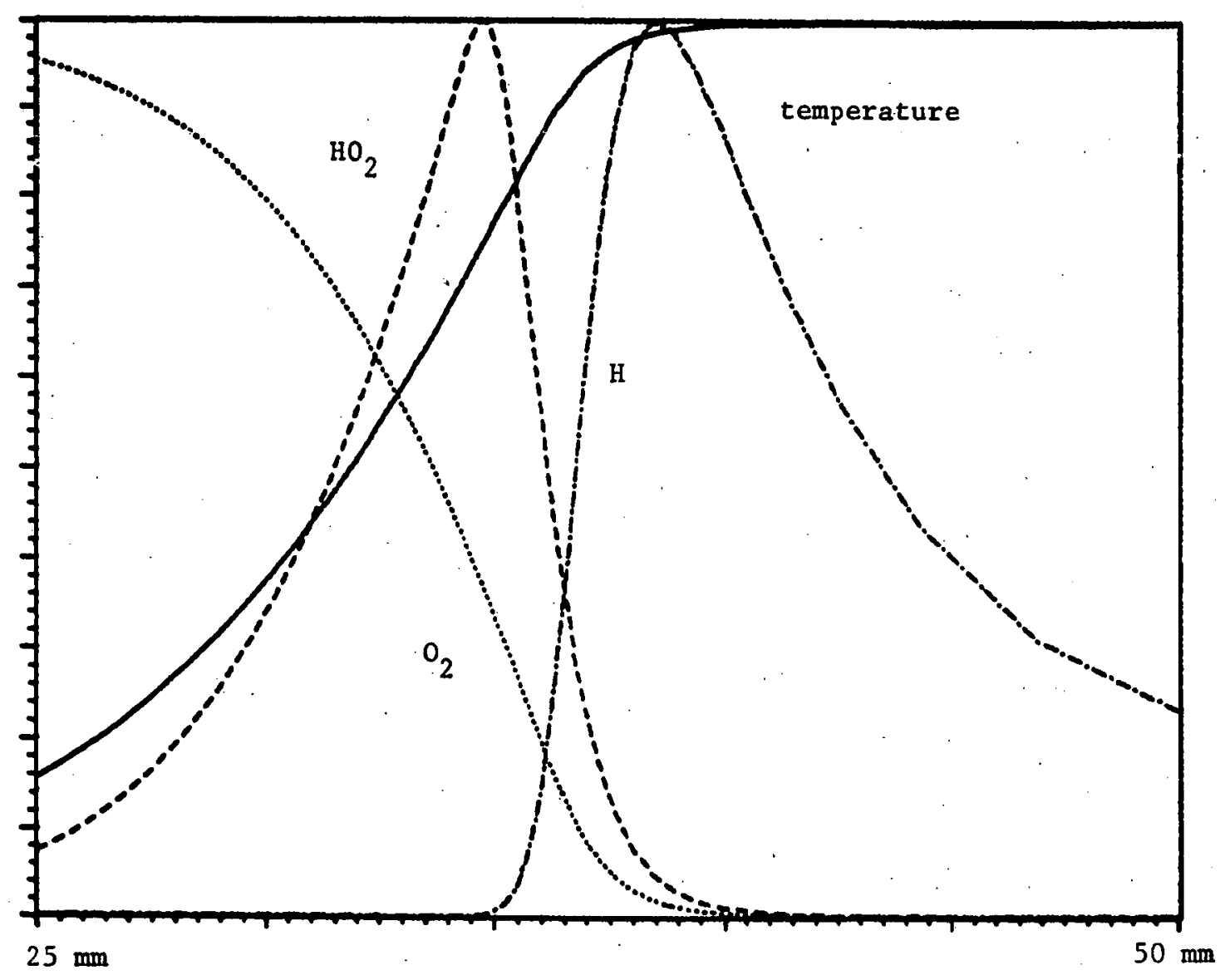

Figure 5.3 .

Computed temperature and species profile

near extinction; in this calculation

$\lambda=21, x_{f}=37.5 \mathrm{~mm}, T_{f}=928 \mathrm{~K} ;$ the

computed flame velocity and flame

temperature are $v_{u}=7 \mathrm{~mm} / \mathrm{s}, \mathrm{T}_{\mathrm{b}}=947 \mathrm{~K}$;

the domain of computation is $(0,500 \mathrm{~mm})$. 


\section{REFERENCES}

[1] D.G. ARONSON \& H.F. WEINBERGER, "Nonlinear diffusion in population genet1cs, combustion and nerve propagation", in Partial Differential Equations and Related Topics, Lecture Notes in Math. 446, SpringerVerlag, New-York, 5-49 (1975).

[2] H. BERESTYCKI, B. NICOLAENKO \& B. SCHEURER, "Travelling wave solutions to combustion models and their singular limits", submitted to Advance in Applied Math.

[3] J. BUCKMASTER \& G.S.S. LUDFORD, "The laminar flame theory", Cambridge University Press, Cambridge (1982).

[4] K.N. CHUEH, C.C. CONLEY \& J.A. SMOLLER, "Positively invariant regions for systems of nonlinear diffusion equations", Indiana Univ. Math. J. 26, 373-392 (1977).

[5] P. CLAVIN \& C. LINAN, "Theory of gaseous combustion", NATO ASI Series "Nonequilibrium Cooperative phenomena in physics and related flelds", M.G. VELARDE, Plenum Press, New-York (to appear).

[ 6 ] T.P. COFFEE \& J.M. HEIMERI "Transport algorithms for premixed laminar steady state flames", Comb. Flame, 43, 273 (1981).

[ 7 ] C.F. CURTISS \& J.O. HIRSCHFELDER, "Transport Properties of Multicomponent Gas Mixtures", J. Chem. Phys. 17, 550 (1949).

[ 8 ] G. DIXON-LEWIS "Flame structure and flame reaction kinetics ،I. Solution of conservation equations and application to rich hydrogenoxygen flames", Proc: Roy. Soc. London 298A, 495 (1967).

[9] G. DIXON-LEWIS "Kinetic mechanism structure and properties of premixed flames in hydrogen-oxygen-nitrogen mixtures", Phil. Trans. of the Royal Soc. London 292, 45 (1979). 
[10] H.A. DWYER, R.J. KEE \& B.R. SANDERS, "Adaptive Grid Methods for problems in Fluid Mechanics and Heat Transfer", AIAA J., 18, 1205-1212 (1980).

[11] H.A. DWYER, M.D. SMOOKE \& R.J. KEE "Adaptive Gridding for Finite Difference Solutions to Heat and Mass Transfer Problems", Numerical Grid Generation, J.F. Thompson Ed., North-Holland, New-York (1982).

[12] P.C. FIFE \& B. NICOLAENKO, "Flame fronts with complex chemical networks", to appear in Proc. CNLS Conference on Fronts, Interfaces and Patterns, Physica D, (1984).

[13] J.M. HYMAN \& M.J, NAUGHTON, "Static Rezone Methods for TensorProduct Grids", Los Alamos National Laboratory report LA-UR-83-3245. (1983).

[14] W.E. JOHNSON "On a first order boundary value problem from laminar flame theory" Arch. Rat. Mech. Anal. 13, 46-55 (1963).

[15] W.E. JOHNSON \& W. NACHBACH, "Laminar flame theory and the steady linear burning of a monopropellant", Arch. Rat. Mech. Anal., 12, 58-91 (1963).

[16] R.J. KEE, J. WARNATZ \& J.A. MILLER "A fortran computer code package for the evaluation of gas-phase viscosities, conductivities, and diffusion coefficients", Sandia National Laboratories Report, SAND83-8209.

[17] R.J. KEE \& J.A. MILLER "Computational modelling of flame structure", Sandia National Laboratories Report, SAND83-8235.

[18] A. KOLMOGOROFF, I. PETROVSKY \& N. PISCOUNOFF : "Etude de l'équation de diffusion avec croissance de la quantité de matière et son application à un problème biologique", Bulletin de I'Univ. d'Etat à Moscou, Série Internat. IA, 1-25 (1937). 
[ 19 ] B. LARROUTUROU "Unsteady one-dimensional flame propagation using adaptive grids", to appear in "Symposium on Numerical Simulation of Combustion Phenomena", (INRIA, May 85), Springer-Verlag.

[20] B. LARROUTUROU, "Mathematical analysis of one-dimensional unsteady flame propagation : existence and unfqueness", to appear.

[21 ] M. LENTINI, "Boundary value problems over semi infinite intervals", Doctoral Thesis, California Institute of Technology (1978).

[22] S.S. LIN, "Theoretical study of a reaction-diffusion model for flame propagation in a gas", Ph.D., Univ. of California, Berkeley (1979).

[23] C.M. LUND, "HCT-a general computer program for calculating phenomena involving one-dimensional hydrodynamics transport, and detalled chemical kinetics", University of California, Lawrence Livermore Laboratory Report UCRL-52504 (1978).

[24] S.B. MARGOLIS, "Time-dependent solution of a premixed laminar flame", J. Comp. Phys. 27, 410 (1978).

[25] M. MARION, "Etude mathématique d'un modèle de flamme laminaire sans température d'Ignition : I-cas scalaire, to appear in Ann. Fac. Sc. Toulouse.

[26] M. MARION, "Qualitative properties of a nonlinear system for laminar flames whithout ignition temperature", Nonlinear Analysis (to appear).

[27] S. MATHUR, P.K. TONDON \& S.C. SAXENA, "Thermal Conductivity of Binary, Ternary and Quaternaty Mixture of Rare Gases", Mo1. Phys., 12, 569 (1967). 
[ 28 ] J.A. MILLER, R.É. MITCHELL, M.D. SMOOKE \& R.J. KEE, "Toward a comprehensive chemical kinetic model for the oxidation of acetylene : comparison of model predictions with results from flame and shock tube experiments, "Nineteenth Symposium (Int'I) on Combustion", The Combustion Institute, Pittsburgh, (1983).

[29] C. NICOLI, "Dynamlqque des flammes prémélangées en présence des mécanismes contrôlant les limites d'inflamabilité", doctorat d'état, Univ. de Provence, Marseille (1985).

[30] N. PETERS \& M.D. SMOOKE "Fluiddynamic-chemical interactions at the lean flammability limit", submitted to Combust. and Flame.

[31 ] M.H: PROTTER \& H.F. WEINBERGER, "Maximum principles in differential equations", Prentice-Hall, Englewood Cliffs, N.J. (1967).

[32] J.J. RAMOS, "On some finite-difference methods for laminar flame calculations", Int. J. for Numerical Methods in Fluid 4, 915-930 (1984).

[33]. M. SERMANGE "Contribution to the numerical analysis of laminar stationary flames", to appear in the proceedings of 1985 AMS-SIAM Summer Seminar.

[34] M. SERMANGE, "Contribution to the numerical analysis of laminar stationary flames", to appear in "Symposium on Numerical Simulation of Combustion Phenomena", (INRIA, May 1985), Springer Verlag.

[35] M.D. SMOOKE, J.A. MILLER \& R.J. KEE "Determination of adiabatic flame speeds by boundary value methods", Combustion Sc. and Tech., 34, 79-90 (1983).

[36] D.B. SPALDING "The theory of flame phenomena with a chain reaction", Phil. Trans. Roy. Soc., London 249A, 1 (1956).

[37] D.B. SPALDING \& P.L. STEPHENSON, "Laminar flame propagation in hydrogen+bromine mixtures", Proc. Roy. Soc. A324, 315 (1971). 
[38] $K$. UCHIYAMA, "The behavior of some nonlinear diffusion equations for large time", J. Math. Kyoto Univ. 18, 453-508 (1978).

[39] J. WARNATZ, "Calculation of the Structure of Laminar Flat Flames, I : Flame Velocity of Freely Propagating Ozone Decomposition Flames, II : Flame Velocity and Structure of Freely Propagating HydrogenOxygen and Hydrogen-Air Flames ; III : Structure of Burner-Stabilized Hydrogen-Oxygen and Hydrogen-Flourine Flames", Ber. Bunsenges. Phys. Chem., 82, 193-200, 643-649 and 834-841 (1978).

[40] J. WARNATZ, "The Structure of Laminar Alkane,Alkene-, and Acetylene Flames", Eighteenth Symposium (Int'1) on Combustion, The Combustion Institute, Pittsburgh 369 (1981).

[41] J. WARNATZ "Influence of Transport Models and Boundary Conditions on Flame Structure", Numerical Methods in Flame Propagation, Eds. N. Peters and J. Warnatz, Friedr. Vieweg and Sohn, Wiesbaden (1982).

[42] J. WARNATZ, "Discussion of test problem B", Numerical methods in laminar flame propagation, a GAMM Workshop, Eds. N. Peters and J. Warnatz, Friedr. Vieweg and Schn. Wiesbaden, (1982).

[43] J. WARNATZ in : W.C. GARDINER, "Flame Chemistry", Springer, New-York, (1980).

[44] H.F. WEINBERGER, "Invariant sets for weakly coupled parabolic and elliptic systems", Rend. Math. Univ. Roma 8, 295-310 (1975).

[45] C.K. WESTBROOK \& F.L. DRYER; "Prediction of Laminar Flame Properties of Methanol-Air Mixtures", Combustion and Flame, 37, 171 , (1980).

[46] K.A. WILDE, "Boundary-value solutions of the one-dimensional laminar flame propagation equations", Combustion and Flame 18, 43 (1972).

[47] F.A. WILLIAMS, "Combustion theory", Addison Wesley, Cambridge, Massachussets (1965). 
[48 ] Ya.B. ZELDOVICH, G.I. BARENBLATT, V.B. LIBROVICH \& G.M. MAHVILADZE, "Mathematical theory of combustion and detonation", Ed. Nauka, Moscow (1980).

\section{Imprimé en France}

pax 
